\title{
EFECTO ANTIINFLAMATORIO DEL EXTRACTO HIDROALCOHÓLICO DE Oenothera rosea (YAWAR SOCCO) EN RATAS CON INDUCCIÓN A LA INFLAMACIÓN AGUDA Y CRÓNICA
}

\author{
Anti-inflammatory effect of hydroalcoholic extract from Oenothera rosea (yawar socco) in rats \\ with induction to acute and chronic inflammation
}

César A Villena $\mathrm{N}^{1}$, Jorge L Arroyo $\mathrm{A}^{2}$

${ }^{1}$ Dirección Técnica - Instituto Quimioterápico S.A.- IQFARMA. Lima, Perú. ${ }^{2}$ Laboratorio de Farmacología, Facultad de Medicina - Universidad Nacional Mayor de San Marcos. Lima, Perú

\section{RESUMEN}

El presente estudio de diseño experimental tuvo como objetivo determinar el efecto antiinflamatorio de Oenothera rosea (Yawar socco) en ratas con inducción de inflamación aguda y crónica. La planta fue secada a $38^{\circ} \mathrm{C}$ en estufa de aire circulante, se molió, y maceró con etanol/ agua $(70: 30)^{1}$. Para evaluar el efecto agudo, se utilizó el modelo experimental de Winter, edema subplantar inducido con carrageninay el edema auricular inducido con xilol. Para la actividad antiinflamatoria crónica se uso el modelo del granuloma inducido por carragenina utilizando una modificación de la técnica descrita por Sedwick y Lees. Se utilizaron 132 ratas albinas con peso promedio 300 g, distribuidas al azar en grupos de 8 cada uno, considerando un grupo control con suero fisiológico de $5 \mathrm{~mL} / \mathrm{kg}$, uno con el agente inductor de inflamación (AI), grupos con AI más extracto en tres dosis y grupos con AI, dexametasona e ibuprofeno; siendo 56 ratas para evaluación frente a la carragenina donde se consideró mililitros de volumen de la subplantar porcentaje de eficacia antiinflamatoria, nivel de PCR en sangre y observación histológica del proceso inflamatorio; primero en 56 ratas frente al xilol expresándose en miligramos de una porción del lóbulo (oreja derecha). Se utilizaron 50 ratones para evaluar toxicidad aguda, 20 ratas normales para la observación de efectos por administración a dosis repetidas durante 28 días. Los resultados mostraron un $60 \%$ dereducción de la inflamación aguda $(p<0,01)$, así como $60 \%$ la inflamación crónica $(p<0,05)$ yla PCR se redujoen $45 \%$ ( $p<0,03)$; no hubo evidencia de efectos adversos, un 60\% del efecto antiinflamatorio en ratas y 60\% del efecto en edema auricular crónico; determinándose una DEM de $61 \mathrm{mg} / \mathrm{kg}$ y sin efectos adversos. Se concluye que en las condiciones experimentales se demostró que el extracto hidroalcohólico de Oenothera rosea en ratas presenta efecto antiinflamatorio y sin cambios hematológicos e histopatológicos en ratas.

Palabras clave: Oenothera rosea (Yawar socco), antiinflamatorio, carragenina, xilol.

\section{SUMMARY}

Thispresentstudyof experimental design hadasaimdeterminestheanti-inflammatoryeffect of Oenotherarosea(Yawarsocco) in ratswhich were induced acute and chronic inflammation. The whole plant was dried at $38^{\circ} \mathrm{C}$ in an oven with circulating air, ground and macerated with a mix ethanol/water (70:30)1. It was used winter experimental model to evaluate the acute state (subplantar edema) induced with carrageenan and the model of xylene-induced edema ear. To determine the chronic inflammatory activity was used the model of carrageenan-induced granuloma using a modification of the technique described by Sedwick and Lees. It was used 132 albino rats of $300 \mathrm{~g}$ randomly divided in groups of eight each, one whereas a control with saline solution $5 \mathrm{~mL} / \mathrm{kg}$, one with the agent that induces inflammation (AI), AI groups and extract in 3 doses also with dexamethasone and ibuprofen, being 56 rats for evaluation against carrageenan where was considered milliliters of subplantar volume, percentage of anti-inflammatory efficacy, blood CRP level and histological examination of the inflammatory process, first in 56 to rats compared toXylene expressing in mg of a piece of lobe. 50 micewere used toassessacutetoxicity, 20 normal rats to seetheeffects of repeated doses in 28 days. Results showed a reduction of $60 \%$ acute inflammation ( $\mathrm{p}<0.01)$ as well as $60 \%$ thechronic inflammation $(p<0,05)$ and CRP was reduced by $45 \%$ $(p<0,03)$; there was noevidence of adverseeffects, a $60 \%$ of anti-inflammatory effect in rats and $60 \%$ of chronic atrial edema effect, determining a MED of $61 \mathrm{mg} / \mathrm{kg}$ and noadverse effects. It's concluded that under theexperimental conditions it showed that hydroalcoholicextract of Oenothera rosea in rats has an antiinflammatory effect in rats has an antiinflammatory effect without hematologic and histopathological changes in rats.

Keywords: Oenothera rosea (Yawar socco), anti-inflammatory, carrageenan, xylol.

\section{INTRODUCCIÓN}

a búsqueda de principios activos para la elaboración de medicamentos ocupa un lugar importante en la investigación. En la amplia flora del Perú se encuentran gran diversidad de especies, muchas de ellas poseen propiedades terapéuticas. Disponer de medicamentos obtenidos de fuentes naturales para diferentes patologías constituye un reto para los investigadores debido al gran número de personas con escasos recursos económicos. La existencia de plantas medicinales que podrían ser utilizadas como complementos o alternativas, a diversas patologías ${ }^{(2,4-6,18)}$.

La presente investigación busca incentivar y valorar el uso de las plantas medicinales. Afianzar 
los conocimientos y costumbres de la población que utiliza Yawar socco en la inflamación, es validar su uso popular y proponer un tratamiento alternativo.

Los objetivos fueron 1) realizar el estudio fitoquímico cualitativo del extracto hidroalcohólico de Oenothera rosea (Yawar socco); 2) demostrar que el extracto posee actividad antiinflamatoria en estados inflamatorios agudos y crónicos inducidos en ratas, comparándolos con ibuprofeno y dexametasona; $y, 3$ ) evaluar la toxicidad aguda en ratones así como la crónica en ratas por administración oral ${ }^{(14)}$.

\section{MATERIALES Y MÉTODOS}

El presente trabajo se realizó en el Bioterio y Laboratorio de Farmacología de la Facultad de Medicina de la Universidad Nacional Mayor de San Marcos.

\section{Recolección de la planta}

La especie Oenothera rosea "Yawar socco" se colectó en la provincia de Huamanga, departamento de Ayacucho, entre los meses de enero a marzo del 2008 a $2800 \mathrm{~m}$ de altitud.

\section{Animales de experimentación}

Se utilizaron 132 ratas cepa Holtzman, machos albinos con peso promedio de $300 \mathrm{~g}$, y 50 ratones machos cepa Balb $\mathrm{C}_{57}$ (Mus musculus) con peso promedio de 26 g, adquiridos del Instituto Nacional de Salud.

\section{Preparación del extracto hidroalcohólico}

Se obtuvo, según el método de CYTED ${ }^{(1)}$ a partir de toda la planta, la cual fue secada a $38^{\circ} \mathrm{C}$ en una estufa con aire circulante.

\section{Estudio fitoquímico preliminar}

$10 \mathrm{~g}$ del extracto hidroalcohólico fueron sometidos a un proceso de partición por el método de cromatografía en columna rápida de silicagel y se corrió utilizando solventes de menor a mayor polaridad (éter etílico, cloroformo, metanoly agua). Los eluatos resultantes fueron secados a temperatura menor de $40^{\circ} \mathrm{C}$, recibiendo las fracciones, nombres según el solvente. Con estas fracciones se realizaron pruebas de identificación de metabolitos. Se realizaron las pruebas de caracterización: de espuma, esteroides, flavonoides, cumarinas, quinonas, y alcaloides ${ }^{(18-19)}$ a una solución acuosa de la muestra $(5 \mathrm{mg} / \mathrm{mL})$.

\section{Efecto antiinflamatorio}

Para el efecto antiinflamatorio se utilizó el Método del Edema subplantar, haciendousodeun pletismómetro. Se administró por vía subcutánea (VSC) o subplantar una pseudosolución de $\lambda$-carragenina, en la aponeurosis plantar de la rata, provocando una reacción inflamatoria.
Se trabajó con 56 ratas albinas de $300 \pm 15 \mathrm{~g}$ de peso corporal, mantenidas en ayuno de 12 horas, en condiciones normales de humedad y temperatura. Se agruparon al azar en siete grupos de individuos cada uno: normal suero fisiológico $2 \mathrm{~mL} / \mathrm{kg}$; carragenina VSC 0,1 mLsolución 2\% (C); $\mathrm{C}$ + extracto $50 \mathrm{mg} / \mathrm{kg} ; \mathrm{C}$ + extracto $250 \mathrm{mg} / \mathrm{kg} ; \mathrm{C}$ + extracto $500 \mathrm{mg} / \mathrm{kg} ; \mathrm{C}+$ dexametasona $2 \mathrm{mg} / \mathrm{kg} ; \mathrm{y}, \mathrm{C}+$ ibuprofeno 25 $\mathrm{mg} / \mathrm{kg}$; los tratamientos fueron administrados por vía oral media hora después de aplicada la carragenina.

Utilizando un pletismómetro manual se midieron los volúmenes normales e inflamados (en $\mathrm{mL}$ ) de la pata posterior derecha de las ratas previamente marcadas, a $1,3,5$ y 7 horas de aplicado el extracto ${ }^{(19)}$.

La medición del efecto antiinflamatorio agudo se realizó por el método del edema auricular, CYTED (1995). Los animales se distribuyeron aleatoriamente en los diferentes grupos. A las ratas se les retiró el alimento 4 horas antes de iniciar el ensayo.

Cincuenta y seis ratas fueron agrupadas en siete grupos de ocho individuos cada uno al azar: 1) Normal suero fisiológico tópico; 2) xylol $20 \mu \mathrm{L} /$ oreja derecha vía tópica $(\mathrm{X})$; 3$) \mathrm{X}$ + extracto $50 \mathrm{mg} / \mathrm{kg}$ vía oral $(\mathrm{VO})$; 4) $\mathrm{X}$ + extracto $250 \mathrm{mg} / \mathrm{kg} \mathrm{VO}$; 5 ) $\mathrm{X}$ + extracto $500 \mathrm{mg} / \mathrm{kg} \mathrm{VO}$; 6) X + dexametasona $2 \mathrm{mg} / \mathrm{kg} \mathrm{VO} ; \mathrm{y}, 7) \mathrm{X}$ + ibuprofeno $25 \mathrm{mg} / \mathrm{kg}$ VO. El xylol fue administrado por vía tópica en tanto que los extractos se suministraron porvía oral. Transcurridas 4 horas después de la aplicación del agente irritante, los animales fueron eutanizados con la administración de pentobarbital $100 \mathrm{mg} / \mathrm{kg}$ vía intraperitoneal; luego se retiró secciones circulares de la oreja (6 mm de diámetro) con ayuda de un sacabocado y se pesaron en balanza de precisión.

La determinación del efecto antiinflamatorio crónico se determinó por el método del granuloma, el cual fue inducido según la técnica de Sedwick y Lees modificada ${ }^{(20)}$. Los animales fueron depilados en la zona dorsal y la nuca, el área depilada fue desinfectada y se procedió a la inyección subcutánea de $20 \mathrm{~mL}$ de aire; al tercer día nuevamente $10 \mathrm{~mL}$ de aire y al cuarto día $2 \mathrm{~mL}$ de una solución de carragenina en la bolsa (los tratamientos fueron administrados desde el primer día dela depilación: suero fisiológico, extracto $50 \mathrm{mg} /$ $\mathrm{kg}$, extracto $250 \mathrm{mg} / \mathrm{kg}$, extracto $500 \mathrm{mg} / \mathrm{kg}$, dexametasona $2 \mathrm{mg} / \mathrm{kg}$ e ibuprofeno $25 \mathrm{mg} / \mathrm{kg}$ ).

Seis horas después de la inyección de carragenina los animales fueron sacrificados por administración de pentobarbital $100 \mathrm{mg} / \mathrm{kg}$ vía intraperitoneal. Procediéndose a la extracción del exudado inflamatorio, se realizó frotis en lámina y se observaron los elementos formes del exudado.

Se extrajo una porción del granuloma y se colocó en formaldehido al 10\% tamponado, para observación histopatológica.

La determinación de la Proteína C Reactiva (PCR) en sangre de ratas se realizó en el Laboratorio Clínico del 
Hospital Nacional Dos de Mayo, utilizando el kit PCR Turbitest AA, los resultados se expresaron en $\mathrm{mg} / \mathrm{mL}$.

\section{Estudio de toxicidad:}

Ladeterminacióndelatoxicidadagudasehizoentreinta y seis ratones normales machos cepa Balb $C_{57}$ que fueron mantenidos en un ambiente a temperatura controlada de 20 $\pm 2{ }^{\circ} \mathrm{C}$ con un ciclo de luz/oscuridad de $12 \mathrm{~h}$. La alimentación fue con ratonina peletizada y agua a voluntad.

Los ratones fueron distribuidos al azar en seis grupos de seis individuos cada uno, el primergrupo recibió solución salina fisiológica $4 \mathrm{~mL} / \mathrm{kg}$; del segundo al sexto se les administró el extracto en dosis de 10, 100, 500, 1000 y 2000 $\mathrm{mg} / \mathrm{kg}$, respectivamente; se les observó constantemente, las primeras 24 horas, y diariamente durante 14 días, registrándose cualquier síntoma de toxicidad.

El estudio de toxicidad subcrónica a dosis repetidas se realizó durante 28 días, con 16 ratas machos cepa Holtzman con peso promedio de $200 \mathrm{~g}$, con agua y comida a libertad. Se les dio, previamente, un periodo de siete días para

\section{RESULTADOS}

Tabla 1. Marcha fitoquímica del extracto hidroalcohólico Oenothera rosea (Yawar socco).

\begin{tabular}{cccccc}
\hline Reactivo & $\begin{array}{c}\text { Metabolitos } \\
\text { secundarios }\end{array}$ & $\begin{array}{c}\text { Éter } \\
\text { etílico }\end{array}$ & Clorofórmico & Etanólico & Acuoso \\
\hline Ninhidrina & Aminoácidos & -- & -- & -- & -- \\
Gelatina & Taninos & +- & - & + & - \\
$\mathrm{Fe} \mathrm{Cl}_{3}$ & Fenoles & + & + & +++ & + \\
Draguendorff & Alcaloides & + & +- & + & - \\
Mayer & Alcaloides & + & +- & + & - \\
Shinoda & Flavonoides & +- & - & + & +- \\
Boertranger & Quinonas & - & - & + & + \\
Molish & Carbohidratos & + & + & + & +- \\
Liebermann & Triterpenos & + & +- & + & - \\
\hline Leyenda: Ausente (-); Poca cantidad (+); Regular Cantidad (++); Abundante cantidad \\
$(+++)$. El estudio fitoquimico revela mayor presencia de compuestos fenólicos.
\end{tabular}

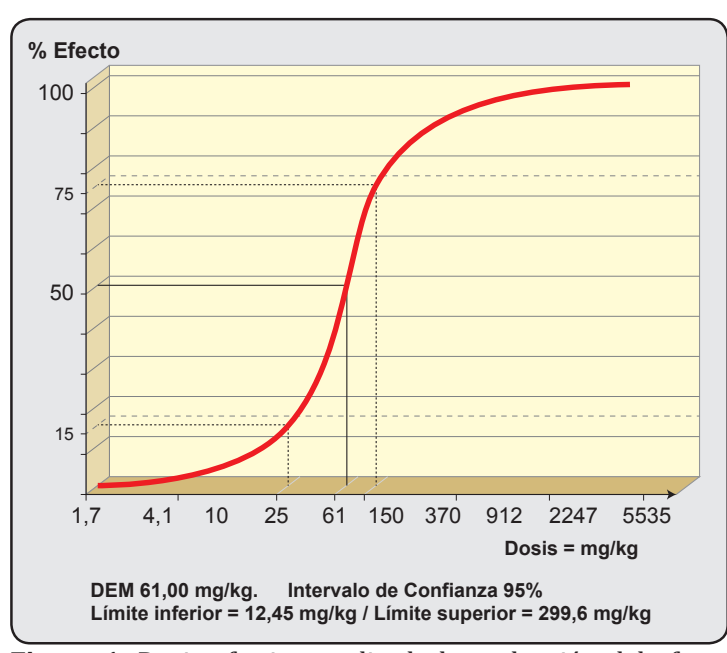

Figura 1. Dosis efectiva media de la evaluación del efecto antiinflamatorio sobre el edema auricular inducido en ratas. adaptación al lugar de experimentación, y se formaron dos grupos al azar. El primero recibió solución salina fisiológica $4 \mathrm{~mL} / \mathrm{kg}$ y el segundo $100 \mathrm{mg} / \mathrm{kg}$ de extracto hidroalcohólico por vía oral durante 28 días, evaluándose semanalmente la evolución del peso corporal. Al final del tiempo, se obtuvieron muestras desangre para buscar posibles cambios a nivel hematológico; luego, los ratones fueron sacrificados y el riñón, corazón, hígado, pulmón, piel y músculos fueron conservados en formol al 10\% para su posterior estudio.

Para el análisis estadístico, los datos fueron agrupados y presentados en tablas, expresándosevalores medios \pm error estándar, en un intervalo de confianza del $95 \%$, porcentajes de eficacia, figuras que explican mejor los hallazgos. Se ha tenido en cuenta una $\mathrm{p}<0,05$ para considerar significativos los hallazgos. Seaplicó un análisis devarianza para establecer la significancia estadística del tratamiento. Se utilizó el programa estadístico SPSS, versión 14, año 2006.

Finalmente, se tomaron en cuenta las consideraciones éticas de una investigación en la que se experimenta con animales.

Tabla 2. Eficacia antiinflamatoria del extracto hidroalcohólico Oenothera rosea (Yawar socco) sobre el edema inducido por xylol.

\begin{tabular}{|c|c|c|c|c|}
\hline Tratamiento & $\begin{array}{c}\text { Valor medio } \\
\text { de } \\
\text { inflamación } \\
(\mathrm{mL})\end{array}$ & $\begin{array}{l}\text { Porcentaje } \\
\text { eficacia anti- } \\
\text { inflamatoria }\end{array}$ & $\begin{array}{c}\text { Relación } \\
\text { al } \\
100 \% \\
\text { efecto }\end{array}$ & $\mathbf{n}$ \\
\hline Normal & 0,0 & 0 & 0 & \\
\hline Xylol & 10,5 & 0 & 0 & \\
\hline Extracto $50 \mathrm{mg} / \mathrm{kg}$ & 9,6 & 8,43 & 55,2 & 6 \\
\hline Extracto $250 \mathrm{mg} / \mathrm{kg}$ & 9,4 & 10,49 & 68,7 & 6 \\
\hline Extracto 500 mg/kg & 8,9 & 15,26 & 100 & 6 \\
\hline Dexametasona 2 mg/kg & 8,9 & 14,79 & & \\
\hline Ibuprofeno 25 mg/kg & 10,2 & 2,86 & & \\
\hline
\end{tabular}
permite el cálculo de la dosis efectiva media. 


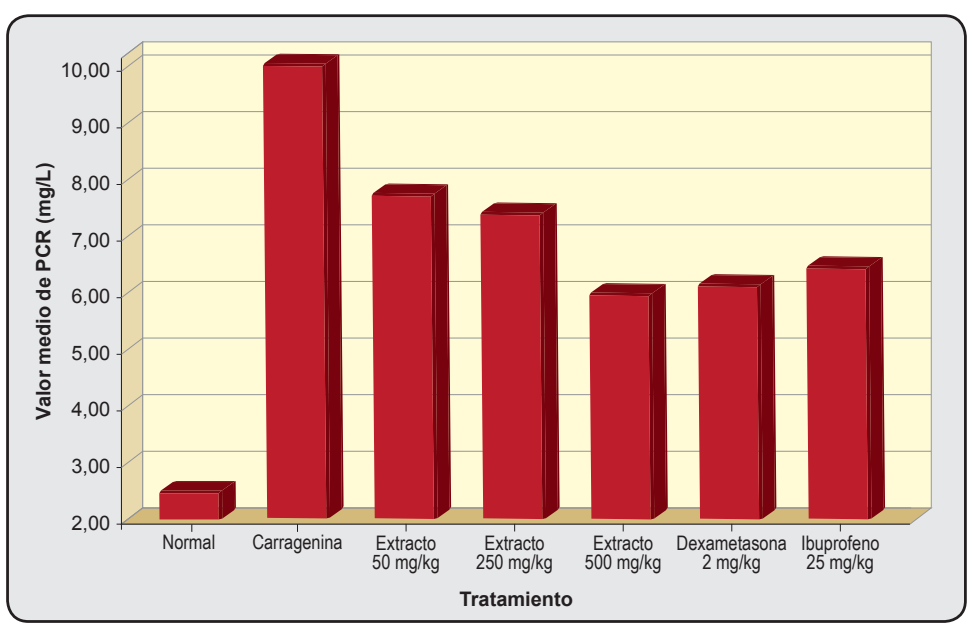

Figura 3. Efecto sobre el nivel de la PCR en ratas por tratamiento de la inflamación.

\section{DISCUSIÓN}

En la presente investigación se evaluaron dos parámetros: el efecto antiinflamatorio por reducción del edema y la eficiencia antiinflamatoria por la reducción porcentual del edema. Se sabe que los procesos inflamatorios agudos aumentan la permeabilidad vascular e inducen la migración de leucocitos y la actividad de especies reactivas: peróxido de hidrógeno $\left(\mathrm{H}_{2} \mathrm{O}_{2}\right)$, anión superóxido $\left(\mathrm{O}_{2}^{-}\right)$e hidroxilo $\left(\mathrm{OH}^{-}\right)$; asimismo, en la inflamación crónica coexisten el daño tisular y los intentos de reparación en diversas combinaciones. Parece que la fase inicial del edema producido por la carragenina se relaciona con la producción de histamina, leucotrienos, factor activador de plaquetas y posiblemente, ciclooxigenasa, mientras que la fase tardía induce una respuesta inflamatoria que se ha relacionado a la infiltración y la producción de radicales libres, así como la liberación de otros mediadores derivados de neutrófilos.

El estudio fitoquímico del extracto etanólico de Oenothera rosea yawar socco, confirma la presencia de metabolitos secundarios: flavonoides, taninos, cumarinas, quinonas y saponinas (Tabla 1). Se sabe que los flavonoides y triterpenos contribuyen con el efecto antiinflamatorio debido a inhibición de la prostaglandina sintetasa, reduciendo el nivel de prostaglandinas en el proceso inflamatorio. Los saponósidos (saponinas) son heterósidos cuya genina puede ser esteroídal (hespirostano o furostano) o triterpénica (oleonano, ursano, damarano); se conoce que las especies vegetales con saponinas y triterpenoides son antiinflamatorios.

La aplicación de drogas que contienen taninos por vía tópica, impermeabiliza las capas más externas de la piel y mucosas, protegiendo así las capas internas, tiene también efecto vasoconstrictor sobre los vasos sanguíneos. Al limitar la pérdida de fluidos e impedir las agresiones externas, los taninos favorecen la regeneración de los tejidos en caso de heridas superficiales. La reparación de heridas incluye procesos de inflamación, proliferación y migración de diferentes tipos de células. Tanto el tratamiento de la piel como la inflamación aguda, generan productos tóxicos conocidos como ROS (especies reactivas de oxígeno).

Los flavonoides son compuestos químicos obtenidos del benzopirano a quienes se les atribuye efectos farmacológicos muy variados: antiinflamatorio, antimicrobiano, antialérgico, hepatoprotector, antitrombótico, antineoplásico, antiulceroso, antidiabético, expectorante, antihemorrágico, diuréticoy antiviral, muchos delos cuales han sido comprobados In vitro e In vivo. Los resultados del edema subplantar, inducido por carragenina, demuestran que el extracto hidroalcohólico de Yawar socco posee efecto antiinflamatorio. Puede afirmarse que la eficacia de los extractos son superiores a los fármacos dexametasona e ibuprofeno, observándose reducción del proceso inflamatorio acorde a la disminución de PCR como resultado de la aplicación del extracto.

La evaluación del producto frente a la inflamación crónica, a través del modelo del granuloma inducido por carragenina en ratas, ha evidenciado efecto antiinflamatorio, confirmado por el estudio histopatológico. Los hallazgos demostraron que Oenothera rosea (Yawar socco) presenta un efecto similar al producido por dexametasona e ibuprofeno.

Otros ensayos, correspondieron a experimentos de inflamación aguda realizados con el modelo de edema auricular inducido por xilol en ratas, demostrándose el efecto dosis dependiente para el extracto, lo cual permitió determinar la dosis efectiva media de 61,0o mg/ kg (figura 1); asimismo, el extracto fue evaluado sobre el modelo experimental del edema subplantar inducido por carragenina en ratas, utilizando el pletismómetro, comprobándose la propiedad antiinflamatoria. Se prefirió el uso de la carragenina para el desarrollo del experimento, porque el edema que se produce esta menos modificado por factores ajenos a los característicos de la inflamación, y porque el efecto antiinflamatorio de este ensayo guarda relación con el efecto antiinflamatorio clínico.

Los resultados histopatológicos del estudio de toxicidad del extracto a dosis repetidas en ratas, administrado por vía oral durante 28 días, no ha revelado 
cambios morfológicos en bazo, corazón, hígado, pulmón y riñón; lo que permite inferir que el extracto es seguro en las dosis evaluadas. La dosis letal 50 (DL50) en ratones resultó ser mayor de $2000 \mathrm{mg} / \mathrm{kg}$ administrada por vía oral.

\section{CONCLUSIONES}

1. El estudio fitoquímico cualitativo del extracto hidroalcohólico de Oenothera rosea (Yawar socco) indica la presencia de abundante cantidad de compuestos fenólicos, seguido de carbohidratos, flavonoides, taninos, triterpenos, quinonas y alcaloides.

2. Sedemostróqueel extracto hidroalcohólicode Oenothera rosea (yawar socco) presenta efecto antiinflamatorio dosis dependiente al reducir el edema subplantar, el proceso inflamatorio crónico y la PCR en ratas.

3. El estudio de toxicidad del extracto hidroalcohólico mostró que la dosis letal 50 (DL50) en ratones es mayor de $2000 \mathrm{mg} / \mathrm{kg}$. Además, el extracto a 100 $\mathrm{mg} / \mathrm{kg}$, durante 28 días, no evidenció cambios hematológicos ni histopatológicos en ratas.

\section{REFERENCIAS BIBLIOGRÁFICAS}

1. CYTED. Programa Iberoamericano de Ciencia y Tecnología para el Desarrollo. Búsqueda de principios activos de planas de la región. Manual de técnicas de investigación. 1995, p. 220.

2. García L, Rojo D, Gómez L, Hernández M. Plantas con propiedades antiinflamatorias. Revista Cubana de Investigaciones Biomédicas. 2002; 21(3): 214-6.

3. Salama A, Navarro L, Díaz F. Actividad antiinflamatoria, dosis letal 50 y estudio fitoquímico preliminar de Cucumis anguria. Revista Colombiana de Ciencias Químico Farmacéuticas 1994; 22: 42-6.

4. Ledó N, Casacó A, Merino N. Gonzáles A, Tolón Z. Efectos antipsoriásico, antiinflamatorio y analgésico del propoleo rojo colectado en Cuba. Revista Cubana de Farmacia 1996; 30(1): 1-6.

5. Morón F, Furones J, Gutiérrez Z. Ausencia de efectos antiinflamatorio y analgésico del extracto fluido de Cymbopogon citratus al 30\% por vía oral. Revista Cubana de Plantas Medicinales 1996; 1(2): 3-6.

6. Miño J, Gorzalczany S, Moscatelli V, Ferraro G, Acevedo C, Hnatyszyn O. Actividadades anticonceptiva y antiinflamatoria de Erythrina crista-galli L. (ceibo). Acta Farm Bonaer. 2002; 21(2): 93-98.

7. Rosa D, Giroud P, Willoughby D. Study of the mediators of acute inflammatory response induced in rats in different sites by carrageenan and turpine. J Pathol 1971; 104(1): 15-29.

8. Vinegar R, Truax J, Selph J. Some qantitative temporal characteristics of carrageenan induced pleurisy in the rat. Proc Soc Exp Biol Med 1973; 143(3): 711-14.

9. Mikami T, Miyasaka K. Effects of several antiinflammatory drugs on the various parameters involved in the inflammatory response in rat carrageenan-induced pleurisy. Eur J Pharmacol 1983; 95(1-2): 1-12.

10. Crunkhon P, Meacock S. Mediators of the inflammation induced in the rat paw by carrageenin. $\mathrm{Br} \mathrm{J}$ Pharmacol 1971; 42(3):392-402.

11. Seibert K, Zhang Y, Leahy K, Hauser S. Pharmacological and biochemical demonstration of the role of cyclooxigenase 2 in inflammation and pain. Proc Natl Acad Sci USA 1994; 91(25): 12013-17.

12. Damas J, Remacle G, Deflandre E. Further studies of the mechanism of counter irritation by turpentine. Naunyn Schmiedebergs Arch Pharmacol 1986; 332(2): 196-200.

13. Lanas A, Piqué J, Pone J. Estrategia clínica para el paciente que precisa antiinflamatorios no esteroides: posición de los inhibidores de la COX-2. Asociación Española de gastroenterologia. 2000; 24: 22-36.

14. Salido M, Abásolo L, Bañares A. Revisión de los antiinflamatoriosinhibidoresselectivosdelaciclooxigenasa-2. Información Terapéutica del Sistema Nacional de Salud. Madrid España. 2001; 25 (2): 46-52.

15. Muller W. Leukocyte-endothelial cell interactions in the inflammatory response. Lab Invest 2002; 82: 521-33.

16. Abramson $S$, Weissmann $G$. The mechanisms of action of nonteroidal anti-inflammatory drugs. Arthritis Rheum 1989; 32(1): 1-9.

17. Domínguez X. Métodos de Investigación Fitoquímica. $3^{\mathrm{a}}$ ed. Limusa. México, 1985. p. 2009-238.

18. Lock de Ugaz O. Investigación Fitoquímica. $2^{\mathrm{a}}$ ed. Editorial Fondo Pontificia Universidad Católica del Perú. Lima, 1994. p. 20-34.

19. Winter CA, Risley EA, Nuss GW. Carrageenin induced edema in the hind paw of the rat as assay for antiinflammatory drugs. Proc Soc Exp Biol Med 1962; 141: 544-47.

2o. Sedgwick AD, Sin YM, Edwards JC, Willoughby DA. Increased Inflamatory reactivity in newly formed lining tissue. J Pathol 1983; 141(4): 483-95.

Manuscrito recibido el: 12/o9/2012

Aceptado para su publicación el: 10/12/2012

\section{Correspondencia:}

Nombre: Cesar Villena Nakamura

Dirección: Jr. Puno 1002- Cercado de Lima, Perú

e-mail: villenanakamura@yahoo.es 